\title{
Использование диатомовых комплексов поверхностных донных отложений для оценки современного состояния крупных арктических водоёмов
}

\author{
Вокуева С.И., Денисов Д.Б. \\ Институт проблем промышленной экологии Севера КНЦ PAH, Anamumbl, s.vokueva@ksc.ru
}

Аннотация. Проведено исследование диатомовых комплексов поверхностных донных отложений крупного арктического водоёма - озера Имандра, изучены пространственные вариации таксономического состава диатомей и структуры сообществ. Выявлены значительные различия современного состояния экосистемы водоёма в различных участках с помощью рассчитанных по диатомовым комплексам показателей и сделан вывод об эффективности их применения для решения задач оценки качества вод. Выделены видыиндикаторы как эвтрофированных, загрязнённых вод, так и олиготрофных условий, которые могут применяться для целей регионального мониторинга и оценки качества крупных Арктических озёр.

Ключевые слова: диатомовые водоросли, биоиндикация, мониторинг, антропогенное загрязнение, пресные водоёмы.

\section{Using diatom assemblages of surface sediments to assess the current state of large Arctic lakes}

Vokueva S.I., Denisov D.B.

Institute of the North industrial environmental problems - the subdivision of Federal Research Center "Kola Science Center RAS", Apatity, s.vokueva@ksc.ru

Abstract. Diatom assemblages of surface sediments of large arctic reservoir (Lake Imandra) and spatial distribution of the taxonomic composition and structure were studied. Significant differences in the current state of the lake ecosystem in different areas were discovered characteristics calculated based on diatom complexes of values. The high-applied, efficiency of the surface diatom analysis for the water quality assessment was shown. Diatoms - indicators for eutrophied and polluted, as well as oligotrophic waters, were revealed. The selected species can be recommended for regional ecological monitoring and water quality assessment of large Arctic lakes.

Key words: diatoms, bioindication, monitoring, anthropogenic pollution, freshwaters.

\section{Введение}

Для оценки состояния экосистем водоемов широко используются диатомовые комплексы (ДК) поверхностных слоёв (0-1 см) донных отложений (ДО) озёр. Они хорошо отражают интегральные характеристики современных условий за период, равный времени накопления сантиметрового слоя ДО, который в условиях высоких широт составляет около 4-10 лет (Моисеенко и др., 2002). Использование современных сообществ фитопланктона в качестве биоиндикатора сопряжено с рядом взаимосвязанных трудностей. Так, непродолжительное «гидробиологическое лето» в арктических регионах характеризуется резкой сменой температурного и гидрологического режимов и определяет значительную вариативность гидробиологических и гидрохимических показателей, когда качественные и количественные показатели фитопланктона могут измениться в течение нескольких суток. При этом, в силу объективных причин, организация отбора проб в сжатые временные сроки на

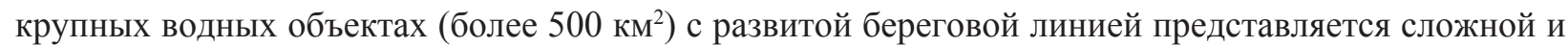
ресурсоемкой задачей, особенно если необходимо провести сравнительный анализ состояния экосистем отдельных участков акватории (Денисов и др., 2019; Вокуева, Денисов, 2019). Поэтому для адекватной оценки пространственных вариаций условий формирования качества вод крупных арктических водоемов целесообразно использовать ДК поверхностных ДО.

\section{Материалы и методы}

Исследования были сосредоточены на одном из самых крупных водоемов Евро-Арктического региона оз. Имандра. Материалом для анализа послужили ДК из поверхностных (0-1 см) слоёв 
ДО различных участков акватории оз. Имандра. Всего было изучено 22 станции (рис. 1, а). Отбор, обработка и анализ проб были осуществлены стандартными общепринятыми методами (Жузе и др., 1949; Давыдова, 1985), по схеме, используемой в ИППЭС ФИЦ КНЦ РАН, описанной ранее (Методы..., 2019). Различия в таксономическом составе и структуре ДК были выполнены методами флористического анализа с помощью программного модуля «Graphs» на основе коэффициента Съеренсена-Чекановского (Новаковский, 2004). Для оценки качества среды на основе ДК были определены индексы сапробности, видового разнообразия Шеннона-Уивера, интегральное значение $\mathrm{pH}$ (Моисеенко, Разумовский, 2009).

\section{Результаты и обсуждение}

В результате проведённого исследования для озера было выявлено 378 таксонов диатомей рангом ниже рода (видов, разновидностей и форм, принадлежащих к 78 родам). Большинство обнаруженных диатомей принадлежат к типично пресноводным, планктонным формам.

Исследование видового состава, включающее в себя анализ количественного распределения диатомей и флористический анализ на основе коэффициента Съеренсена-Чекановского, фактически разделило озеро на две части: были выделены два крупных участка акватории с близким видовым составом, отражающим сходные условия обитания: 1 - плёс Большая Имандра и северная часть

a)

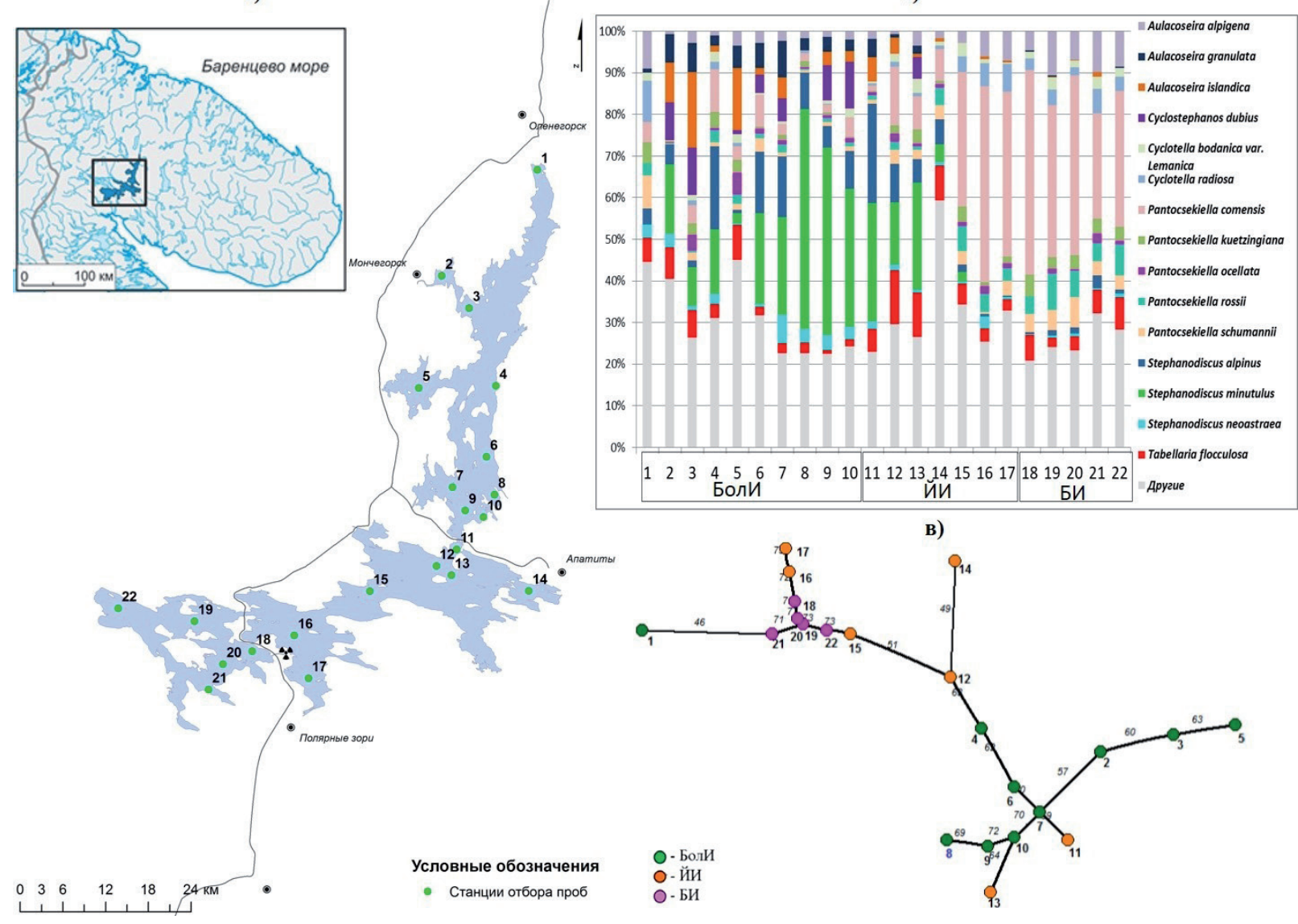

Рис. 1. а) Карта-схема оз. Имандра и расположение станций отбора проб; б) относительная численность видов по станциям отбора проб; в) результаты анализа диатомовых комплексов на основе коэффициента флористического сходства Съеренсена-Чекановского по количественным показателям (БолИ - Большая Имандра, ЙИ - Йокостровская Имандра, БИ - Бабинская Имандра).

Fig. 1. a) Map of Lake Imandra and the location of sample stations; b) relative abundance of diatom species in sample stations; c) results of the analysis of diatom assemblages by the coefficient of floristic similarity of SorensenChekanovsky, on quantitative indicators (BolI - Bolshaya Imandra, JI - Jokostrovskaya Imandra, BI - Babinskaya Imandra). 
Йокостровской Имандры, с комплексом доминирующих видов Stephanodiscus minutulus (Kütz.) Cleve \& Möller, Aulacoseira islandica (O.Müller) Simonsen, Stephanodiscus alpinus Hust., Cyclostephanos dubius (Hust.) Round, и Aulacoseira granulata (Ehrenberg) Simonsen; 2 - центральная и западная часть Йокостровской Имандры и плёс Бабинская Имандра, где доминанты представлены видами Pantocsekiella comensis (Grun.) K.T.Kiss \& E.Ács, Aulacoseira alpigena (Grun.) Kramm., Pantocsekiella rossii (H.Håk.) K.T.Kiss \& E.Ács, Pantocsekiella schumannii (Grun.) K.T.Kiss \& E.Ács и Cyclotella radiosa (Grun.) Lemm. (рис. 1, б, в). Особые условия формирования качества вод отмечаются в губах Куреньга (ст. 1), Вите (ст. 5) и Тик-губа (ст. 14).

Рассчитанный по ДК индекс видового разнообразия Шеннона-Уивера (Н') в различных участках акватории оз. Имандра характеризуется значительной вариабельностью (от 2.5 до 4.5 бит/экз.) (рис. 2, а), что свидетельствует о широком спектре условий для развития водорослей. Максимальные значения индекса характерны для участков, где сочетаются речные и озёрные условия - заливы, куда впадают реки и где развивается высшая водная растительность, что обогащает диатомовые комплексы эпифитными и бентосными видами. А наименьшие показатели Н' наблюдаются, в том числе, в районах эвтрофируемых и загрязняемых участков: губы Белой (ст. 8) и транзитной зоны «юг БолИ - север ЙИ», испытывающих непосредственное загрязнение стоками апатитовой промышленности и городов Кировск и Апатиты, поступающими в озеро со стоком реки Белая. Степень антропогенной трансформации хорошо прослеживается и по распределению рассчитанных по ДК значениям $\mathrm{pH}$ и индекса сапробности. Наибольшие значения $\mathrm{pH}$ (7.4-7.5) и индекса сапробности (1.8-1.9), наблюдаются в южной части БолИ, в том числе в районе губы Белой (рис. 2, б, в), где в то же время более 60 \% диатомовых водорослей являются алкалифилами, развивающимися при значениях $\mathrm{pH}$ около 7.5. Полученная информация подтверждает значительные поступления в этот участок биогенных веществ с щелочными стоками. Достаточно высокие показатели рН и индекса сапробности отмечаются также в участках акватории, подверженных влиянию предприятий цветной металлургии (губа Монче, ст. 2 и 3), что совместно с наивысшими значениями степени загрязнения ДО за индустриальный период токсическими элементами указывает на значительную антропогенную нагрузку в этом районе. При этом меньшие значения индекса в сравнении с показателем для губы Белой могут быть объяснены угнетающим токсическим влиянием на некоторые доминирующие в других станциях виды, уменьшающим тем самым значение индекса сапробности.

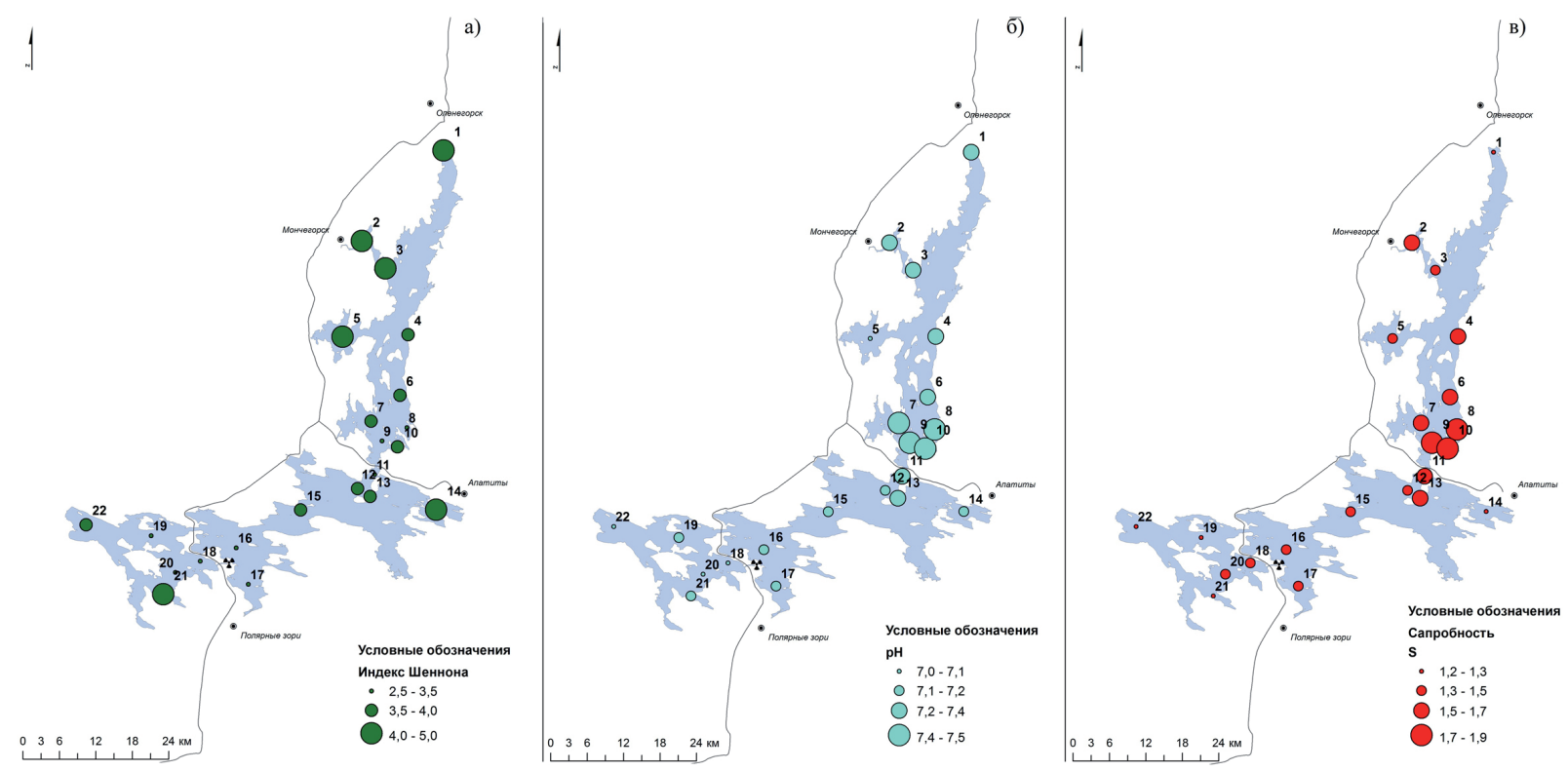

Рис. 2. Распределение вычисленных значений а) индекса Шеннона-Уивера; б) рН; в) индекса сапробности на карте озера.

Fig. 2. Distribution of the calculated values of a) the Shannon-Weaver index; b) $\mathrm{pH}$; c) the saprobity index on the lake map. 


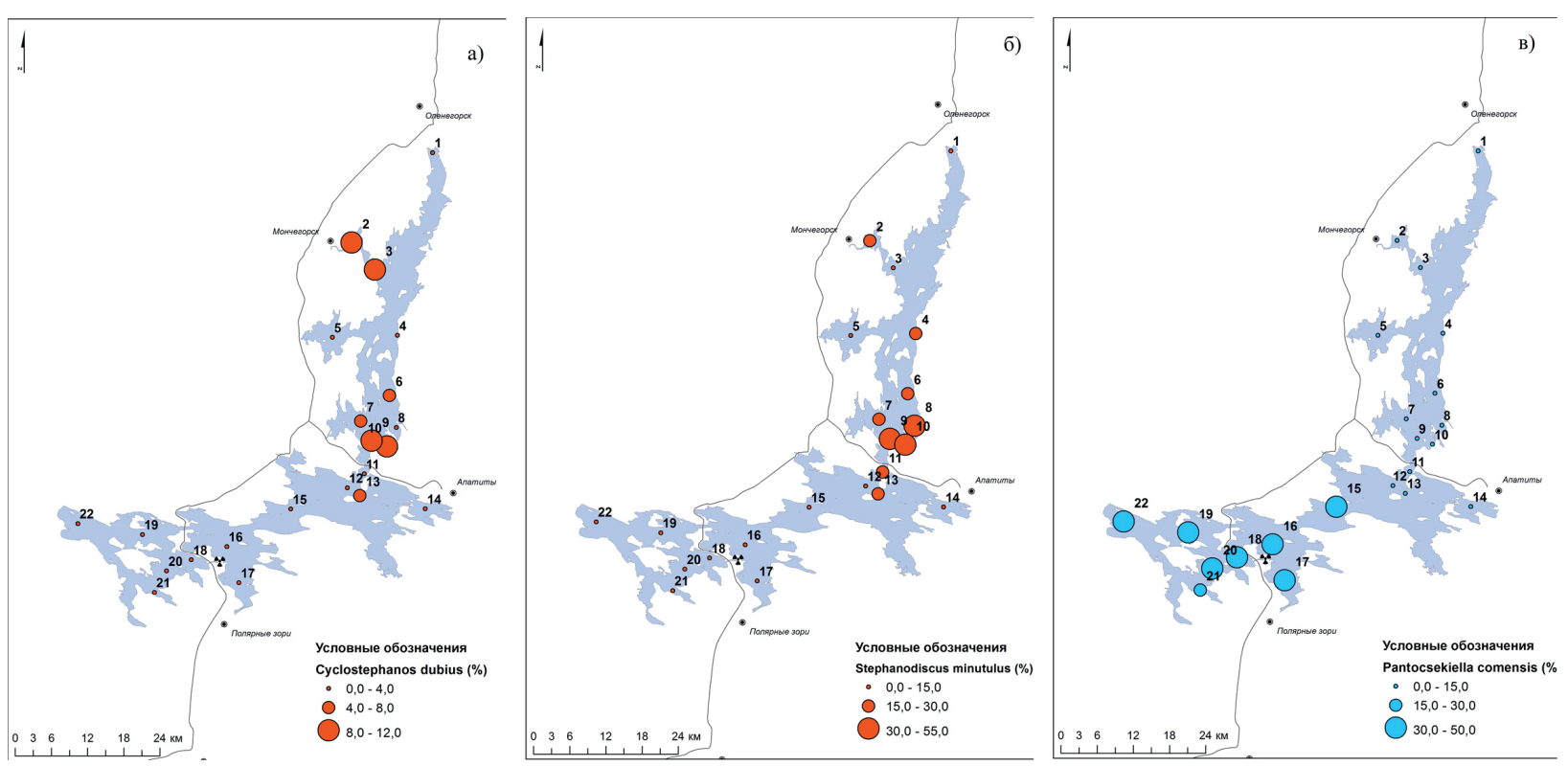

Рис. 3. Относительная численность (\%) видов-индикаторов а), б) загрязнённых и в) незагрязнённых вод.

Fig. 3. Relative abundance (\%) of species-indicators of a), b) polluted and c) unpolluted waters.

Кроме того, распределение относительной численности массовых видов диатомей позволило выделить виды-индикаторы конкретных условий, как олиготрофных, так и эвтрофных, по содержанию которых также можно определить степень антропогенной трансформации водоёма в отдельных его участках. Наибольшие количества эвтрофных видов (Aulacoseira granulata, A. islandica, Cyclostephanos dubius, Stephanodiscus alpinus, S. minutulus u S. nеoastraea), характеризующиеся положительными связями со многими загрязняющими веществами и исследуемыми показателями, наблюдаются в зоне максимального промышленного влияния - в БолИ и в северной части ЙИ (рис. 3, а, б). Кроме того, разновидности Stephanodiscus характеризуются отдельно как индикатор токсической нагрузки, принимая минимальные значения относительной численности в губе Монче, при интенсивном развитии остальных эвтрофных видов. Олиготрофные же виды (Aulacoseira alpigena, Cyclotella radiosa, Pantocsekiella comensis, P. rossii) максимально распространены в самых неподверженных антропогенным изменениям районах - в западной части ЙИ и в БИ (рис. 3 , в).

\section{Заключение}

В результате проведённого исследования сделан вывод о целесообразности применения ДК поверхностных ДО в целях оценки современного состояния экосистем пресноводных объектов, в особенности крупных водоёмов в условиях Арктических широт. Так как поверхностные слои ДО представляют интегральные характеристики за последние годы, это позволило корректно оценить состояние озера Имандра в наиболее важных участках, как напрямую подверженных антропогенному влиянию, так и теоретически не испытывающих его.

Исследование показателей, рассчитанных по ДК, и выявленных видов-индикаторов показало, что наиболее близкие к естественно-природным условия характерны для плёса Бабинская Имандра и западной части Йокостровской Имандры, не испытывающих прямого техногенного загрязнения. Участки акватории, подверженные влиянию стоков апатитового производства, отличаются интенсивными процессами эвтрофирования вод, и характеризуются низким таксономическим разнообразием, высокими индексами сапробности и значениями $\mathrm{pH}$, а также увеличенными содержаниями видов-индикаторов загрязнённых вод. В зоне воздействия стоков предприятий цветной металлургии также помимо биогенного загрязнения выявлены последствия токсической нагрузки. Кроме того, выделенные индикаторные виды качества вод и состояния экосистемы могут быть самостоятельно использованы для задач регионального мониторинга и оценки качества крупных Арктических озёр, а также при разработке региональных систем нормирования антропогенной нагрузки. 


\section{Литература}

1. Вокуева С.И., Денисов Д.Б. Оценка состояния экосистемы озера Имандра по диатомовым комплексам донных отложений // Сборник материалов Всероссийской студенческой научно-технической конференции СНТК-2019. Мурманск: Изд-во МГТУ. 2019. С. 187-189.

2. Давыдова Н.Н. Диатомовые водоросли - индикаторы экологических условий водоёмов в голоцене / Н.Н. Давыдова. Л.: Наука. 1985. 244 с.

3. Денисов Д.Б., Косова А.Л., Вокуева С.И. Перспективные направления биоиндикации качества пресных вод в Арктике // Труды XVI Ферсмановской научной сессии, 2019. № 19. С. 146-150.

4. Жузе А.П., Прошкина-Лавренко А.И., Шешукова В.С. Диатомовый анализ. Кн. 1. Москва-Ленинград: Государственное издательство геологической литературы. 1949. 239 с.

5. Методы экологических исследований водоемов Арктики: монография / С.С. Сандимиров [и др.]. Мурманск: Изд-во МГТУ. 2019. 180 с.

6. Моисеенко Т.И., Даувальтер В.А., Лукин А.А., Кудрявцева Л.П., Ильяшук Б.П., Ильяшук Е.А., Сандимиров С.С., Каган Л.Я., Вандыш О.И., Шаров А.Н., Шарова Ю.Н., Королева И.М. (под ред. Моисеенко Т.И.) Антропогенные модификации экосистемы озера Имандра. М: Наука. 2002. 487 с.

7. Моисеенко Т.И., Разумовский Л.В. Новая методика реконструкции катионно-анионного баланса в озеpax (диатомовый анализ) // Докл. Академии наук. Т. 427. 2009. №1. С. 132-135.

8. Новаковский А.Б. Возможности и принципы работы программного модуля «Graphs» / Автоматизация науч. исследований. Сыктывкар: Изд-во Коми науч. центра УрО РАН. 2004. Вып. 27.31 с. 